\title{
Defects of colour vision: A review of congenital and acquired colour vision deficiencies
}

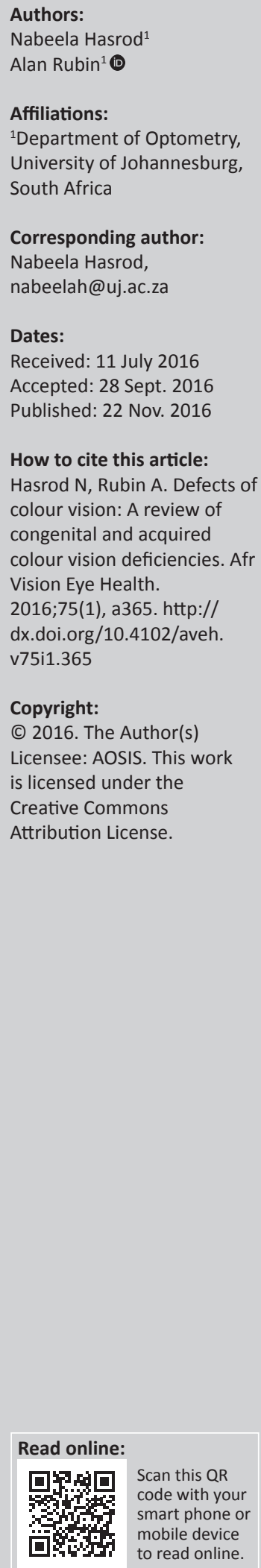

Colour vision deficiencies (CVDs) can be categorised as being congenital or acquired. Some CVDs are already present at birth, as inherited conditions that are the result of changes at the photo-pigment level and are non-pathological, incurable and do not change over time. Examples are red-green defects which are inherited as an X-linked recessive trait. Acquired CVD develops secondary to ocular and systemic conditions or as a side effect of certain medications or sometimes toxic effects of chemicals, and trauma and ageing can also be important in some CVDs.

\section{Introduction}

Colour vision is the ability of an organism to distinguish objects based on the wavelengths (or frequencies) of the light they reflect, emit or transmit. ${ }^{1,2}$ A person's perception of colours is a sensitive and subjective process whereby the brain responds to the stimuli that are produced when incoming light reacts with the several types of photoreceptor cells in the retina and signals are sent through to the occipital cortex of the brain. ${ }^{3}$ Deeb and Motulsky ${ }^{4}$ describe two classes of photoreceptors that occur within the human retinae: rods, which are responsible for vision in dim light, and cones, which mediate vision in bright lighting conditions and are important for form and colour vision. There are three types of cones that have overlapping peak spectral responsivities. They are the long-wavelength cones (L-cones), which have a peak sensitivity at approximately $560 \mathrm{~nm}$ corresponding to a greater sensitivity to red; the medium-wavelength cones (M-cones), which are maximally responsive to green at $530 \mathrm{~nm}$; and the short-wavelength cones (S-cones); which have a peak sensitivity at $430 \mathrm{~nm}$ that relates to colour sensitivity to blue. ${ }^{5}$ However, the overlap between these three spectra of absorption allows the brain to discriminate colour on the basis of wavelength, providing comparisons of photon absorptions by the different cones. ${ }^{6}$ The sensitivity of this colour sense, therefore, increases the susceptibility to colour defects that may occur because of toxins, or ocular or systemic disease. ${ }^{7}$

\section{Literature review}

People with normal colour vision have all three functioning, long-, medium- and shortwavelength, cones and have the ability to see the full spectrum of colours within the visible $380 \mathrm{~nm}-700 \mathrm{~nm}$ portion of the electromagnetic spectrum. ${ }^{5}$ These people are known as normal trichromats, as normal colour perception is also known as trichromacy. ${ }^{8}$ A colour vision deficiency occurs when one or more cones are absent or possess abnormal function. Therefore, people who possess colour vision deficiencies (CVDs) see fewer separate hues in their environment, thereby confusing colours that would normally be easily distinguishable by normal trichromats. ${ }^{9}$

\section{Classification of colour vision deficiencies}

CVDs are typically classified according to the number of primary colours that are needed to match all spectral hues. ${ }^{9}$ People with an inherited colour defect are classified as anomalous trichromats, dichromats or monochromats. ${ }^{10}$

Classification of CVD according to the cone pigment affected and the number of primary colours needed to match spectral hues is illustrated in Figure 1.

Celesia ${ }^{11}$ mentions that monochromats are typically totally colour blind, having an inability to distinguish wavelength differences, and may only have one cone pathway in addition to the rod pathway, and either complete or incomplete monochromacy may occur. Complete monochromats possess abnormal cones within a disrupted foveal mosaic, visual acuity is typically $6 / 36-6 / 30$ with the presence of an absolute central scotoma, nystagmus and photophobia, and the prevalence 


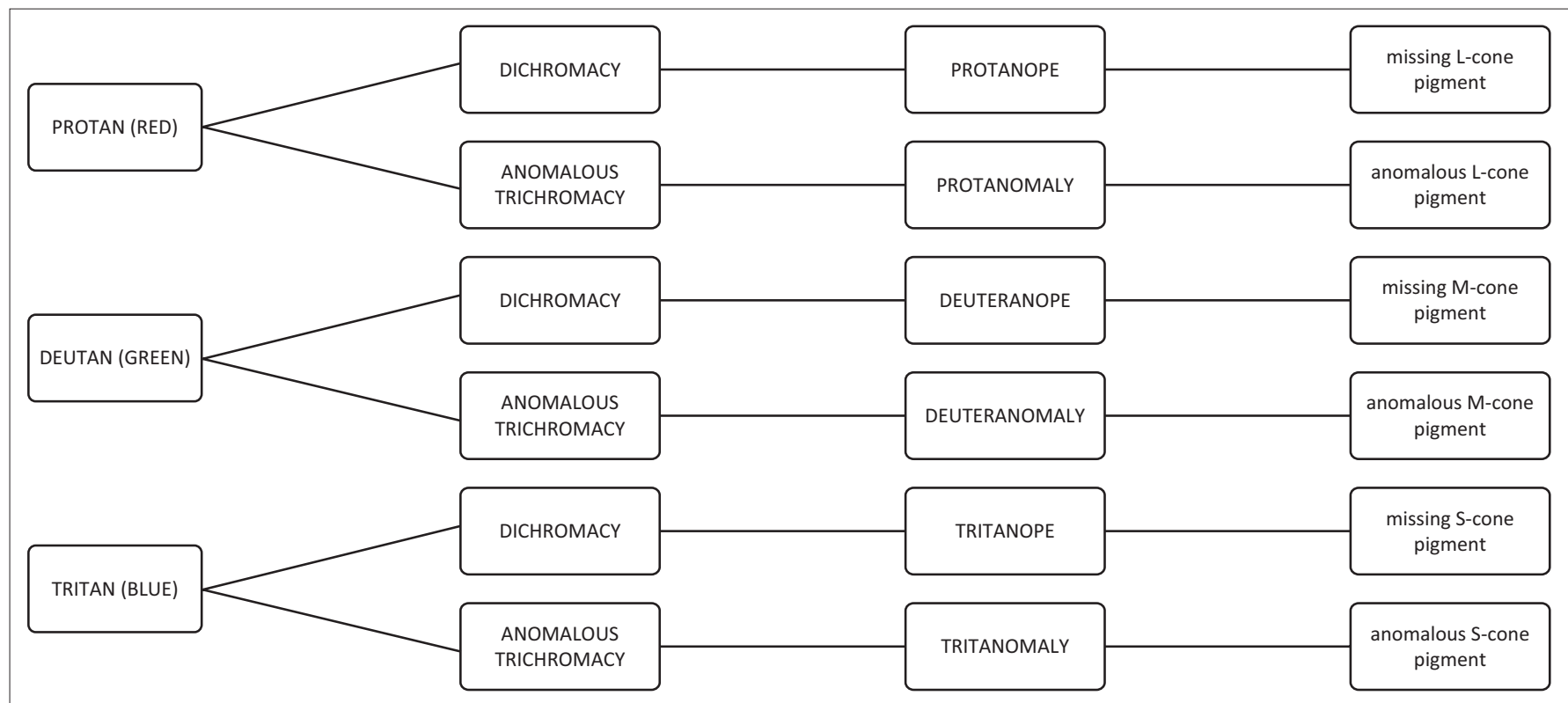

FIGURE 1: Flow diagram illustrating colour vision deficiencies.

is 1 in 35 000. Incomplete monochromacy involves the S-wavelength cones only, and individuals can discriminate some hues in mesopic (average lighting) conditions when $\mathrm{S}$-cones and rods are active. Visual acuity is about $6 / 18$ with a relative central scotoma, moderate nystagmus and photophobia and an irregular foveal mosaic. The prevalence ${ }^{12}$ of incomplete monochromacy is 1 in 100000.

Dichromacy and anomalous trichromacy can be classified according to the affected cone photo-pigment. Dichromats have a cone photo-pigment missing; therefore, they only have two functional cones and cone channels and use only two primary colours. Anomalous trichromats have all three cone photo-pigments; however, one cone photo-pigment is anomalous having a shifted peak sensitivity and they use three primary colours in a mixture to match any colour but require a different intensity of each primary colour as compared with a normal trichromat. A milder colour deficiency occurs when one or more of the three cones function poorly, whereas a more severe form occurs when one of the three cone types does not function entirely. ${ }^{10}$ Total achromatopsia results where there is a loss of all three cone types and achromats can only attempt to match any colour to any other colour by adjustment of relative brightness. ${ }^{9}$

\section{Types of congenital colour vision deficiencies}

Three terms are used to describe CVD: 'protanopia', 'deuteranopia' and 'tritanopia'. ${ }^{13}$ A protanope has the longer wavelength cone (corresponding to red colours of the visible electromagnetic spectrum) photo-pigment absent or abnormal in function, and a deuteranope and a tritanope have the middle and shorter wavelength cone photo-pigments (which correspond to green and blue electromagnetic spectrum wavelengths, respectively) missing or anomalous in function, respectively. ${ }^{12}$
Whilst in normal observers the maximum sensitivity occurs at a wavelength of $555 \mathrm{~nm}$ (as measured in a vacuum), in protanopia the maximum sensitivity occurs at about $535 \mathrm{~nm}$ and there is a marked reduction in sensitivity above $600 \mathrm{~nm}$ (a shortening of the red end of the spectrum). The shift in maximum sensitivity in deuteranopia and tritanopia is less pronounced. Maximum sensitivity in deuteranopia is at $565 \mathrm{~nm}$ and in tritanopia it is at $555 \mathrm{~nm}$. Tritanopes have reduced sensitivity at the blue end of the spectra. The relative luminous efficiency of anomalous trichromats falls in between that of the trichromats and the corresponding dichromats. ${ }^{12}$

The main types of congenital CVDs are often known as redgreen deficiencies and blue-yellow deficiencies. ${ }^{3}$

\section{Red-green colour deficiencies}

Cole $^{14}$ stated that red-green colour deficiencies from problems with either the L-cones or M-cones are the most common types of colour deficiency and affect more men than women ( 1 in 12 men has red-green CVDs compared with only 1 in 200 women). People who present with these types of colour deficiencies confuse colours in the red-yellow-green spectrum. ${ }^{10}$

Deuteranopia occurs when there is an absence of M-cones (green-sensitive retinal photoreceptors) and is a form of dichromatism in which there are only two cone pigments present and the CVD is usually hereditary and sex-linked. Deuteranomaly is a less severe hereditary and sex-linked form of red-green colour deficiency (mildly affecting redgreen hue discrimination in 5\% of European males) and is caused by an anomalous shift in the green-sensitive retinal receptors and problems of distinguishing different shades of the same colour in the red-yellow-green spectrum are present. $^{12,15}$ 
Protanopia is hereditary, gender-linked and present in about $1 \%$ of males. It can be defined as a loss of L-cones caused by the complete absence of red retinal photoreceptors and protanopes confuse colours in the red-yellow-green spectrum. ${ }^{3,16}$ Protanopia is a severe type of CVD in which the subject can only perceive light wavelengths from $400 \mathrm{~nm}$ to $650 \mathrm{~nm}$, instead of the more usual $700 \mathrm{~nm}$. Pure reds cannot be seen and appear black, purple colours are indistinguishable from blues, orange-tinted reds may appear as very dim yellows and all orange-yellow-green shades appear as a similar yellow hue. ${ }^{14}$ Protanomaly is a less severe form in which an altered spectral sensitivity of red-sensitive retinal receptors (closer to green receptor response) results in poor red-green hue discrimination and subjects have problems distinguishing different shades of the same colour in the redyellow-green spectrum. ${ }^{9}$

\section{Blue-yellow colour deficiency}

Tritanopia is a rare deficiency relating to Chromosome 7 and is not linked to the sex chromosomes, and, therefore, it occurs equally in men and women. This deficiency, associated with an absent or anomalous S-cone photo-pigment, occurs when there are only two cone pigments present and there is a total absence of blue-sensitive retinal receptors; therefore, blues appear greenish, yellows and oranges appear pinkish and purple colours appear deep red. Tritanomaly is the milder form of the condition. ${ }^{12}$

\section{Inheritance of colour vision deficiencies}

CVDs at the retinal level occur when the instructions for the development of the photo-pigments in one or more of the cone cells are defective. The cone cells may be absent or, in the case of the L- and M-cones, may be anomalous in terms of being less sensitive to light, or the visual pathway may not have developed correctly. ${ }^{17}$ The highest prevalence of CVD in the general population occurs with red-green colour defects and the pattern of inheritance is X-linked recessive, thus occurring predominantly in males, but is transmitted by females with $8 \%$ of the female population being carriers. ${ }^{18}$

Neitz and Neitz ${ }^{19}$ have explained that red-green colour deficiency genes are located on the 23rd chromosome on the long arm of the X-chromosome within the X928 band; therefore, a male who possesses a CVD has the defective gene on the X-chromosome and a female who possesses a CVD has the defective gene on both the X-chromosomes. A female with the defective gene on only one of the X-chromosomes will be a carrier. A male can inherit a CVD if his mother is either a carrier or possesses a CVD, whereas a female with a CVD must have a father who is colour deficient as well as a mother who is a carrier. This is why red-green colour vision deficiency is far more common in men than in women (as mentioned earlier, 1 in 12 men has a red-green CVD compared with only 1 in 200 women).
The blue pigment genes reside on the 7th chromosome and a blue-yellow CVD affects both men and women equally because it is carried on a non-sex chromosome and has an autosomal dominant inheritance. This type of CVD is much rarer than red-green $\mathrm{CVD} .^{20}$

Inheritance of CVD according to the defective $\mathrm{X}$-chromosome $\left(X^{D}\right)$ is illustrated in Table 1.

\section{Acquired colour vision deficiencies}

Similar to congenital or inherited colour deficiencies, acquired CVDs can also be classified as Type 1 or Type 2 redgreen deficiencies and Type 3 blue-yellow colour deficiency. ${ }^{1}$

Type 1 exhibits protan deficiency characteristics with an altered protan spectral luminosity function, in which the wavelength of maximum sensitivity is shifted towards shorter wavelengths., ${ }^{21,22}$ Type 2 acquired red-green colour defects are similar to a deutan deficiency but there is greater reduction in short-wavelength sensitivity, that is, chromatic discrimination deficit along the red-green axis with a milder blue-yellow loss. ${ }^{21,22}$ Type 3 is a tritan-like defect, sometimes also referred to as blue-yellow defect. It may be accompanied by a shift of maximum luminance sensitivity to shorter wavelengths (pseudo-protanomaly) as well as variable deviations in visual acuity. ${ }^{21}$

Acquired colour deficiencies are less easy to classify than congenital CVD, but their detection and classification may be an important diagnostic aid. The changes in colour vision are frequently used to monitor ocular pathology and assess treatments. ${ }^{22}$ According to Schwartz, ${ }_{r}^{23}$ Kollner's rule, which may be applied to acquired colour defects, states that acquired blue-yellow colour defects are the result of changes in the ocular media, choroid and diseases occurring in the outer retinal layers, whilst acquired red-green defects are the result of changes in the optic nerve and more inner parts of the visual pathway. Thus, the usual changes in the crystalline lens because of ageing produce an acquired blue-yellow colour defect. This rule is useful for the early stages of a condition; however, because of the nature and progression of acquired colour defects, it may not apply when the disease has progressed to an advanced stage.

Figure 2 shows the associated ocular diseases related to the classification of acquired CVD.

TABLE 1: Inheritance of colour vision deficiencies from parent to offspring.

\begin{tabular}{|c|c|c|c|c|c|c|}
\hline \multirow[t]{2}{*}{ Male parent } & \multicolumn{2}{|c|}{$\begin{array}{c}\text { Carrier female } \\
\text { parent } \dagger\end{array}$} & \multicolumn{2}{|c|}{$\begin{array}{l}\text { CVD female } \\
\text { parent } \$\end{array}$} & \multicolumn{2}{|c|}{$\begin{array}{c}\text { NT female } \\
\text { parent }\end{array}$} \\
\hline & $X^{D}$ & $X^{N}$ & $X^{D}$ & $X^{D}$ & $X^{N}$ & $X^{N}$ \\
\hline \multirow[t]{2}{*}{ NT male parent $\left(X^{N} Y\right)$} & $x_{D} X^{n}+$ & $X^{N} X^{N}$ & $X^{D} X^{N} \uparrow$ & $x^{D} X^{N}+$ & $X^{N} X^{N}$ & $X^{N} X^{N}$ \\
\hline & $X^{D} Y \S$ & $X^{N} Y$ & $X^{D} Y \S$ & $X^{D} Y \S$ & $X^{N} Y$ & $X^{N} Y$ \\
\hline \multirow[t]{2}{*}{ CVD male parent $\S\left(X^{D} Y\right)$} & $X^{D} X^{D}$ & $X^{N} X^{D} \dagger$ & $X^{D} X^{D}+$ & $X^{D} X^{D}$ & $X^{N} X^{D} \dagger$ & $X^{N} X^{D} \dagger$ \\
\hline & $X^{D} Y \S$ & $X^{N} Y$ & $X^{D} Y \S$ & $X^{D} Y \S$ & $X^{N} Y$ & $X^{N} Y$ \\
\hline
\end{tabular}

$X^{N} X^{N}$, female with normal trichromatic colour vision; $X^{N} Y$, male with normal trichromatic colour vision; $X^{D}$, colour vision defective $X$-chromosome; $X^{N}$, colour normal $X$-chromosome; $Y$, Y-chromosome; CVD, colour vision deficiencies; NT, normal trichromatic colour vision.

$\dagger, X^{D} X^{N} ; 末, X^{D} X^{D}$ represent the genes of a female carrier of the defective gene; $\S, X^{D} Y$ represents a male who possesses a CVD. 


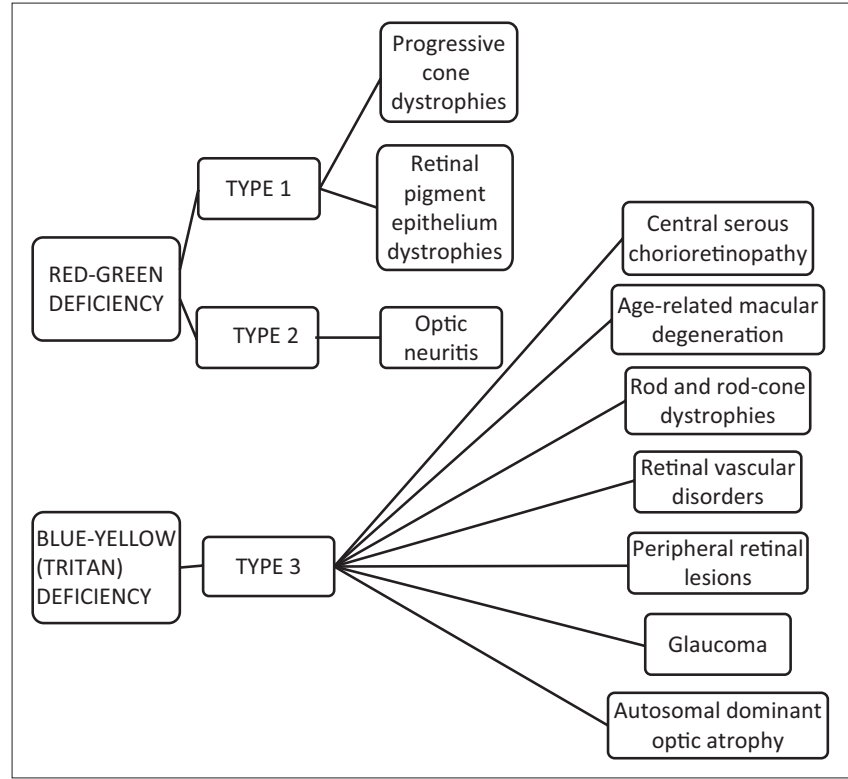

FIGURE 2: Flow diagram illustrating the classification of acquired colour vision deficiencies and associated ocular pathologies.

\section{Acquired colour vision defects in glaucoma}

Glaucoma is defined as and applied to a collection of acute or chronic optic neuropathies that feature a loss of retinal ganglion cells and excavation, or cupping, of the optic nerve head. ${ }^{24}$ Several studies have identified that an acquired tritan deficiency on conventional colour tests, such as the F-M 100Hue and desaturated D-15 tests, is associated with early glaucoma, ${ }^{25}$ whilst some patients present with acquired protan-deutan deficiencies in the advanced stages. ${ }^{26}$ Although white-on-white threshold perimetry remains the gold standard for detecting and monitoring the loss of visual function in primary open-angle glaucoma, approximately one-third or more of the optic nerve axons may be lost before a field defect can be detected. Therefore, recent research focusses on the usefulness of colour discrimination tests in the early detection and monitoring of progression of the disease. ${ }^{27}$

Papaconstantinou et al. ${ }^{28}$ in their study on acquired colour vision and visual field defects in patients with ocular hypertension and early glaucoma, identified that colour defects predetermine a group of ocular hypertensive patients who have a very high probability of developing glaucoma in later years regardless of the Humphrey's visual field test parameters because CVDs precede the glaucomatous defects. Their study showed that those patients who later developed severe glaucomatous defects in the Humphrey's visual field tests initially produced poor total error scores on colour vision tests, whereas patients who never appeared to have such defects had a total error score in colour perception testing that did not show major fluctuations. Thus, colour vision in primary open-angle glaucoma progressively deteriorates highlighting damage to retinal ganglion cells, which can be quantitatively evaluated by testing colour vision perception.

Colour vision testing is always performed monocularly when acquired colour deficiency is suspected or when monitoring for possible progression of ocular disease. ${ }^{29}$ The assessment of simple manual colour vision tests to detect Type 3 (tritanlike) deficiencies in patients with ocular hypertension primary open-angle glaucoma suggested that best results were obtained from a combination of the City University and Hardy Rand and Rittle (HRR) test scores, and this combination could provide useful additional data on colour vision in glaucoma screening programmes. ${ }^{30}$

One advantage of using computer-generated colour tests is their ability to test neuronal processing at specific retinal locations, giving them the potential to be used to detect and monitor ocular disease in a way similar to standard whiteon-white perimetry. ${ }^{27}$ Computer-generated colour tests have provided the means for isolating the processing of chromatic signals from the accompanying achromatic cues with the observer's task being to detect a stimulus whose chromaticity is modulated in various directions of chromatic space on a background of varying chromaticities, and recent investigations of chromatic discrimination using computergenerated colour tests have shown that colour contrast thresholds are elevated in patients with glaucoma. ${ }^{31}$

An example of computerised colour vision testing systems to evaluate acquired colour defects is the Cambridge colour test, which was developed using the basic principles of traditional pseudo-isochromatic plates and modern technology of randomised luminance to evaluate colour function or discrimination. ${ }^{32}$ Another recent computerised test used in occupational environments is the colour assessment test developed by Birch et al., ${ }^{33}$ which is based on a spatiotemporal luminance masking technique, where part of a uniform background is formed by spatially discrete elements that are equal in time-averaged luminance with respect to the background, and during the stimulus presentation, each element scintillates whilst its luminance varies. ${ }^{31,33}$ Rabin et al. ${ }^{34}$ have also developed a new computer-based, conespecific (long, medium, short) contrast sensitivity test, the Rabin cone contrast test, which uses a randomised series of red, green and blue letters visible to a single cone type (long, medium or short) in decreasing steps of contrast to measure the threshold for letter recognition in order to identify the type and severity of CVD. ${ }^{31,34}$ Computer emulations of clinical colour vision tests, such as HRR, Ishihara and City University tests, are also available. Therefore, quantitatively assessing colour vision provides a useful means for detecting diseases such as early glaucomatous changes in patients with normal visual fields. ${ }^{27}$

\section{Acquired colour vision deficiencies caused by pharmacotherapy}

Because of the complex nature of colour vision, deficiencies as a side effect of certain drugs often occur before the presentation of other visual function defects; therefore, it is sometimes possible to identify the early onset of side effects of drugs by colour vision examinations. ${ }^{26,35}$ In terms of the eye, drugs can affect all the tissues but often affect either the retina or optic nerve. As mentioned earlier, according to 
Kollner's rule, retinopathies cause tritan or blue-yellow deficiencies combined with a red shift of the Rayleigh match (a mixture of red and green light sources to be matched with a yellow light source) with a protan-like luminosity. Redgreen defects are caused by damage to the optic nerve (optic neuropathies) and are associated with an enlarged range of Rayleigh matching and a deutan-like luminosity. ${ }^{23,36}$

Table 2 summarises the effects of certain drugs on colour vision and is characterised according to the manifestation of impairment, that is, either retinopathy or optic neuropathy. The table mentions only a few classes of substances, and exceeding the prescribed dosage, prolonged usage or the development of hypersensitivity to the offending drug or chemical could be the reason for substance toxicity affecting colour vision. $36,37,38,39$

\section{Incidence and prevalence of colour vision deficiency}

The incidence of CVD differs in race and geographical regions because of it being a genetic disorder. ${ }^{19}$ A larger percentage of colour deficiencies have been found in those of European origin ( $8 \%$ in men and $0.5 \%$ in women) as compared to male of African $(3 \%-4 \%)$ or Asian $(3 \%)$ origin. Dichromats as a group have more abnormal colour vision than anomalous trichromats. However, dichromats were experimentally shown to be more proficient than observers with normal redgreen colour vision in detecting texture boundaries of target objects that are camouflaged by colour. ${ }^{3}$

\begin{tabular}{|c|c|c|}
\hline $\begin{array}{l}\text { Generic } \\
\text { drug name }\end{array}$ & Drug usage & $\begin{array}{l}\text { South African } \\
\text { drug brand name }\end{array}$ \\
\hline \multicolumn{3}{|c|}{$\begin{array}{l}\text { Retinopathies: } \\
\text { Blue-yellow deficiencies }\end{array}$} \\
\hline \multirow[t]{3}{*}{ Chloroquine } & Antimalarial & Mirquin \\
\hline & Amoebiasis & Nivaquine \\
\hline & Rheumatologic treatment & - \\
\hline \multirow[t]{5}{*}{ Indomethacin } & NSAID & Adco-Indogel \\
\hline & - & Adco-Indomethacin \\
\hline & - & Betacin \\
\hline & - & Flamecid \\
\hline & - & Sandoz-Indomethacin \\
\hline Phenothiazine & Antipsychotics & Mellaril \\
\hline Thioridazine & - & - \\
\hline Tridione & Anti-epileptic & Temazepam \\
\hline \multirow[t]{2}{*}{ Digoxin } & Congestive heart & Lanoxin \\
\hline & Failure treatment & Purgoxin \\
\hline \multirow[t]{3}{*}{ PDE5-inhibitors } & Erectile dysfunction & Viagra \\
\hline & $\begin{array}{l}\text { Pulmonary hypertension } \\
\text { treatment }\end{array}$ & Cialis \\
\hline & - & Levitra \\
\hline \multicolumn{3}{|c|}{$\begin{array}{l}\text { Optic neuropathies: } \\
\text { Red-green deficiencies }\end{array}$} \\
\hline \multirow[t]{3}{*}{ MAO-inhibitors } & Antidepressants & Marplan \\
\hline & - & Niamid \\
\hline & - & Parnate \\
\hline \multirow[t]{3}{*}{ Ethambutol } & Antituberculotic & Rifafour \\
\hline & - & Rimstar \\
\hline & - & Sandoz Ethambutol $\mathrm{HCl}$ \\
\hline
\end{tabular}

PDE, phosphodiesterase; MAO, monoamine oxidase inhibitors; NSAID, nonsteroidal antiinflammatory; $\mathrm{HCl}$, hydrochloride.
TABLE 3: Prevalence of congenital colour deficiencies.

\begin{tabular}{lcc}
\hline $\begin{array}{l}\text { Types of colour } \\
\text { vision deficiency }\end{array}$ & Males & Females \\
\hline Overall & $\sim 8$ & $\sim 0.5$ \\
Anomalous trichromacy & 1 & 0.01 \\
Protanomaly & 5 & 0.4 \\
Deuteranomaly & Rare & Rare \\
Tritanomaly & & \\
Dichromacy & 1 & 0.01 \\
Protanopia & 1.5 & 0.01 \\
Deuteranopia & 0.008 & 0.008 \\
Tritanopia & & \\
Monochromacy & Rare & Rare \\
Rod monochromacy & Rare & Rare \\
Cone monochromacy & Very rare & Very rare \\
Atypical monochromacy & &
\end{tabular}

All numbers in the table are percentages.

Table 3 summarises the prevalence of congenital colour deficiencies amongst males and females for the general population. $^{13}$

\section{Conclusion}

CVD can be either congenital or acquired. Congenital colour deficiencies are caused by inherited photo-pigment abnormalities and reasons for an acquired CVD may be ocular pathology, intracranial injury, excessive use of therapeutic drugs or unintentional drug exposure. The terms 'protan', 'deutan' and 'tritan' represent the colour deficiencies involving the absence or abnormality of a single photopigment. Acquired CVDs have been classified in a way similar to congenital CVDs, with two types of protan-deutan deficiencies (Type 1 and Type 2) and one type that has tritanlike defects of colour (Type 3). The primary difference between congenital and acquired CVDs is that genetic deficiencies present bilaterally at birth with congenital CVD, whereas acquired CVD can be unilateral, asymmetric or even transient. ${ }^{40}$ The detection and classification of CVD, specifically acquired colour defects, may be an important diagnostic aid in monitoring the changes in colour vision associated with ocular pathology and assessing treatments.

\section{Acknowledgements Competing interests}

The authors declare that they have no financial or personal relationship(s) that may have inappropriately influenced them in writing this article.

\section{Authors' contributions}

N.H. wrote the manuscript as part of her Masters dissertation under supervision by A.R. Review of the initial draft, supervision and approval of the manuscript was by A.R.

\section{References}

1. Formankiewicz M. Assessment of colour vision. Optom Today. 2009;49:28-34.

2. Pease PL. Colour vision. In: Benjamin IM, Borish WJ, editors. Borish's clinical refraction. 2nd ed. Missouri: Butterworth-Heinemann, 2006; p. 289-355. 
3. Gouras P. Colour vision. New York: Elsevier; 2009.

4. Deeb SS, Motulsky AG. Colour vision defects. In: Rimoin DL, Connor JM, Pyeritz RE, Korf BR, editors. Emery and Rimoin's principles and practice of medical genetics. 6th ed. Massachusetts: Academic Press, 2001; p. 1-16.

5. De Valois KK, De Valois RL. Color Vision. In: De Valois KK, editor. Seeing. California: Academic Press, 2000; p. 129-170.

6. Nathans J, Thomas D, Hogness DS. Molecular genetics of human color vision Genes encoding blue, green, and red pigments. Science. 1986;232:193-202. http://dx.doi.org/10.1126/science.2937147

7. Mollon JD, Pokorny J, Knoblauch K. Normal and defective colour vision. Oxford: Oxford University Press; 2003.

8. Mollon JD. Colour vision. Annu Rev Psychol. 1982;33:41-85. http://dx.doi. org/10.1146/annurev.ps.33.020182.000353

9. Birch J. Color vision tests: General classification. In: Foster DH, editor. Inherited and acquired colour vision deficiencies. Boca Raton, FL: CRC Press, 1991; p. 215-234.

10. Fairchild MD. Chapter 1. Human colour vision. In: Fairchild MD, editor. Colour appearance models. New York: Wiley, 2005; p. 1-34.

11. Celesia GG. Colour vision deficiencies. In: Daube JR, Mauguière F, editors Disorders of visual processing- handbook of clinical neurophysiology. New York: Elsevier, 2005; pp. 251-269.

12. Birch J. Diagnosis of defective color vision. Oxford: Oxford University Press; 1996.

13. Kalloniatis M, Luu C. Colour perception. From: Webvision: The Organisation of the Retina and Visual System. WordPress; 2011. [eBook]

14. Cole BL. Assessment of inherited colour vision defects. Clin Exp Optom. 2007;90:157-175. http://dx.doi.org/10.1111/j.1444-0938.2007.00135.x

15. Francois J. Hereditary in ophthalmology. St Louis, MO: Mosby; 1961.

16. Rushton WAH. A cone pigment in a protanope. J Physiol. 1963;168:345-359. http://dx.doi.org/10.1113/jphysiol.1963.sp007196

17. Kraskel H, Moreland JD. 1991. Colour vision deficiencies in ophthalmic disease. In: Foster DH, editor. Inherited and acquired colour vision deficiencies. Boca Raton, FL: CRC Press, 1991; p. 115-172.

18. Deeb SS, Kohl S. Genetics of colour vision deficiencies. Dev Ophthalmol. 2003;37:170-187. http://dx.doi.org/10.1159/000072046

19. Neitz J, Neitz M. The genetics of normal and defective colour vision. Vision Res. 2011;51:633-651. http://dx.doi.org/10.1016/j.visres.2010.12.002

20. Smith DP, Cole BL, Isaacs A. Congenital tritanopia without neuroretinal disease. Invest Ophthalmol. 1973;12:608-617.

21. Verriest G. Further studies on acquired deficiency of color discrimination. J Opt Soc Am. 1963;531:85-195. http://dx.doi.org/10.1364/josa.53.000185

22. Dain SJ. Clinical colour vision tests. Clin Exp Optom. 2004;87:76-293. http:// dx.doi.org/10.1111/j.1444-0938.2004.tb05057.x

23. Schwartz S. Visual perception: A clinical orientation. 4th ed. New York: The McGraw Hill Companies; 2004.
24. Weinrib RN, Aung T, Medeiros FA. The pathophysiology and treatment of glaucoma: A review. JAMA. 2014;311:1901-1911. http://dx.doi.org/10.1001/ jama.2014.3192

25. Sample PA, Weinrib RN, Boynton RM. Acquired dyschromatopsia in glaucoma. Surv Ophthalmol. 1986;31:54-64. http://dx.doi.org/10.1016/0039-6257(86)90051-2

26. Simunovic MP. Acquired colour vision deficiency. Surv Ophthalmol. 2016;61:132155. http://dx.doi.org/10.1016/j.survophthal.2015.11.004

27. Pacheco-Cutillas M, Sahraie A, Edgar DF. Acquired colour vision defects in glaucoma - Their detection and clinical significance. Br J Ophthalmol. 1999;83 1396-1402. http://dx.doi.org/10.1136/bjo.83.12.1396

28. Papaconstantinou D, Georgalas I, Kalantzis G, et al. Acquired colour vision and visual field defects in patients with ocular hypertension and early glaucoma. Clin Ophthalmol. 2009;3:251-257.

29. Pokorny J, Smith VC, Verriest G, Pinckers AJLG. Congenital and acquired colour vision defects. New York: Grune and Stratton; 1979.

30. Heron G, Erskine NA, Farquharson E, Moore AT, White H. Colour-vision screening in glaucoma - The tritan album and other simple tests. Ophthalmic Physiol Opt. 1994;14:233-238. http://dx.doi.org/10.1111/j.1475-1313.1994.tb00003.x

31. Niwa Y, Muraki S, Naito F, Minamikawa T, Ohji M. Evaluation of acquired color vision deficiency in glaucoma using the Rabin cone contrast test. Invest Ophthalmol Vis Sci. 2014;55:6686-6690. http://dx.doi.org/10.1167/iovs.14-14079

32. Hasrod N, Rubin A. Colour vision: A review of the Cambridge colour test and other colour testing methods. AVEH. 2015;74:1-7. http://dx.doi.org/10.4102/aveh.v $74 \mathrm{i} 1.23$

33. Birch J, Barbur JL, Harlow AJ. New method based on random luminance masking for measuring isochromic zones using high resolution colour displays. Ophthalmic Physiol Opt. 1992;12:133-136. http://dx.doi.org/10.1111/j.1475-1313.1992.tb 00275.x

34. Rabin J, Gooch J, Ivan D. Rapid quantification of colour vision: The cone contrast test. Invest Ophthalmol Vis Sci. 2011;52:816-820. http://dx.doi.org/10.1167/ iovs.10-6283

35. Li J, Tripathi RC, Tripathi BJ. Drug-induced ocular disorders. Drug Saf. 2008;31: 127-141. http://dx.doi.org/10.2165/00002018-200831020-00003

36. Jaeger W, Krastel H. Colour vision deficiencies caused by pharmacotherapy. In: Verriest G, editor. Colour vision deficiencies VIII. Dordrecht: Marthinus Nijhof, 1987; p. 27-50

37. Bailey JD, Fraunfelder FT, Neitz J. Colour vision deficiency: A concise tutorial for optometry and ophthalmology [homepage on the Internet]. [cited 2016 May 23]. Available from http://www.richmondproducts.com/files/8013/0590/4424/ Color_Vision_Deficiency_Tutorial_042511.pdf

38. Tait DM, Caroll J. Colour blindness: Acquired. In: Besharse JC, Bok D, editors. The retina and its disorders. Oxford: Academic Press, 2011; p. 134-140.

39. Santaella RM, Fraunfelder FW. Ocular adverse effects associated with systemic medications. Drugs. 2007;67:75-93. http://dx.doi.org/10.2165/00003495-2007 67010-00006

40. Karpecki PM, Shechtman DL. Color me curious. Rev Optom. 2013;150:100-102. 